\title{
PERPUSTAKAAN LAB
}

\author{
Anthony Christianto ${ }^{1)}$, Budi Adelar Sukada ${ }^{2)}$
}

1)Program Studi S1 Arsitektur, Fakultas Teknik, Universitas Tarumanagara, anthony_christianto@yahoo.com

2) Program Studi S1 Arsitektur, Fakultas Teknik, Universitas Tarumanagara, budisukada@yahoo.com

\begin{abstract}
Abstrak
Generasi milenial merupakan sebuah jenjang generasi yang lahir pada tahun 1980-2000 yang memiliki keinginan untuk mengembangkan potensi diri, diakui, serba instan dan paham lebih dalam di bidang teknologi. Milenial yang seyogyanya merupakan pelopor dalam perkembangan berbasis teknologi wajib dibekali oleh pelbagai edukasi, baik secara mandiri maupun kolaboratif, dalam mendukung individu menciptakan berbagai inovasi untuk masa depan yang lebih baik, agar mencapai tingkat aktualisasi diri yang nyata. Untuk menunjang aktivitas tersebut, diperlukan wadah bagi para milenial dalam melakukan pembelajaran eksperimental maupun secara sosial dan kontekstual dalam mencari ilmu pengetahuan yang lebih dalam. Sesuai dengan metode tipologi perkembangan fungsionalitas perpustakaan dari prototipe hingga stereotipe, kehadiran perpustakaan lab diharapkan dapat menjadi salah satu solusi bagi para milenial untuk mendapatkan edukasi teknologi yang mutakhir dan komprehensif, baik secara pengalaman langsung melalui laboratorium-laboratorium praktik yang bersifat eksperimental, maupun melalui koleksi buku teoritikal yang diselingi dengan ruang-ruang diskusi untuk membuka wawasan yang lebih luas akan pengetahuan tentang teknologi. Perpustakaan lab diharapkan dapat menghadirkan nilai-nilai kesejamanan bagi para pengguna milenial yang menggunakan wadah tersebut untuk belajar, berkreasi, berkolaborasi secara kelompok dan mandiri atau sebagai tempat pelesiran sementara yang disatukan di dalam satu atap sebagai ruang edukatif untuk pengembangan diri generasi milenial.
\end{abstract}

Kata kunci: kolaborasi; milenial; pengembangan diri; perpustakaan; teknologi

\begin{abstract}
The millennial generation is a periodical generation that includes people who were born in the year 1980-2000 who have the will to improve oneself, to be acknowledged, do things instantly and have a deeper understanding about technology. This generation that is well known for pioneering in the field of technological development should be provided with a range of education, both independently or collaboratively, so as to support each individual in creating various innovation for a better future, thus achieving the real self-actualization. To support it, an open space should be available for the millennials to conduct experimental or social and contextual learning for understanding the technological knowledge better. According to the method of the developmental stages of building typology ranging from the prototypical to the stereotypical, the presence of lab-rary (lab library) hopes to give a solution for the millennials to be supplied with the sophisticated and comprehensive technological education, through hands-on experience via experimental laboratory, or a diverse range of theoritical book collection that is accompanied with discussion rooms throughout the plan to enhance the collaborative learning of technology and its advancements. Lab-rary hopes to provide the contemporaneity values for the millennial users that use it as a place to study, co-create, collaborate in a team or as a temporary playroom all built under one single roof that vows to create a living educational platform for the self-improvement of millennials.
\end{abstract}

Keywords: collaborate; library; millennial; self-improvement; technology 


\section{PENDAHULUAN}

Di era digital dengan perkembangan pesat dalam bidang teknologi, budaya baca dalam lingkup masyarakat milenial sudah mulai luntur dan tergantikan oleh kepraktisan gawai dan koneksi internet dalam memberikan informasi yang cepat. Ketergantungan yang tinggi terhadap hal-hal yang bersifat instan berdampak pada menurunnya kualitas intelektual manusia dan berpengaruh langsung kepada proses perkembangan diri.

Sebagai salah satu sarana dalam mengembangkan potensi masyarakat milenial, perpustakaan dirancang untuk mewadahi kegiatan-kegiatan yang dapat menunjang pengembangan diri masingmasing pengguna. Ditargetkan memiliki mayoritas pengguna atau pengunjung yang berusia 22 sampai 27 tahun, atau golongan karyawan fresh graduate yang sudah menduduki usia produktif dan mendapatkan pekerjaan, perpustakaan ini diharapkan dapat menjadi wadah third space bagi mereka. Perpustakaan tidak lagi hanya menyediakan ruang bagi pengguna untuk mencari informasi secara mandiri, tetapi juga diusulkan sebagai wadah pertemuan bagi segala lapisan masyarakat yang memiliki keterikatan akan hal yang sama (common interest).

Seiring dengan perkembangan jaman, perpustakaan tidak lagi berpusat kepada koleksi dan arsip media cetak (buku, jurnal, majalah, surat kabar, naskah) yang disediakan untuk kepentingan publik, tapi juga dapat berperan sebagai suatu wadah bagi masyarakat untuk bereksperimen, mencoba pengalaman baru yang memungkinkan untuk melahirkan ide-ide kreatif yang bersifat orisinil dan otentik agar dapat dimanfaatkan sebagai suatu nilai keterampilan lebih yang secara langsung mendukung laju pertumbuhan ekonomi kreatif di lingkungan sekitar.

Perpustakaan dirancang sebagai 'living room', dimana kegiatan di dalam meliputi dialog, interaksi, kolaborasi dan sharing, layaknya bertamu satu sama lain untuk sekedar berbagi pengalaman maupun pengajaran yang bertujuan untuk mengembangkan potensi yang dimiliki oleh masing-masing individu. Wadah pertemuan ini dipergunakan sebagai tempat untuk berinteraksi antar sesama, baik milenial maupun non-milenial, ahli dan amatir, untuk berbagi berbagai macam keterampilan, baik soft skill maupun hard skill, yang dirangkul dalam wadah laboratorium praktik yang digunakan untuk sistem pembelajaran eksperimental maupun sosial dan kontekstual, melahirkan suatu inovasi baru agar dapat bersaing secara global.

Dalam perkembangannya, perpustakaan diharapkan tidak hanya menampung arsip-arsip media cetak konvensional yang berwujud konkrit dan nyata, tetapi juga dapat menampung gagasan-gagasan kreatif yang lahir dari dalam diskusi maupun praktik masyarakat yang bersifat maya dan nyata yang bertujuan untuk memajukan taraf kehidupan manusia secara global.

Sebagai salah satu living space untuk masyarakat milenial dan non-milenial, perpustakaan bukan hanya dirancang sebagai surga pecinta buku, tetapi untuk siapapun yang ingin berdialog satu sama lain, mengembangkan kemampuan masing-masing dalam aspek keterampilan ataupun sekedar menghabiskan waktu luang mendalami pengalaman baru.

Visi dari perpustakaan ini adalah menciptakan nuansa kondusif bagi masyarakat milenial untuk dapat berkolaborasi dan berinteraksi satu sama lain sebagai wujud untuk mengembangkan diri.

Untuk mendukung visi tersebut, perpustakaan memiliki beberapa misi :

- Menyediakan wadah laboratorium eksperimental (software dan hardware) untuk berkreasi dengan memanfaatkan teknologi, berinteraksi secara kolaboratif, serta belajar bersama.

- Mengaplikasikan kemajuan teknologi dalam bidang edukasi agar sesuai dengan perkembangan jaman.

\section{KAJIAN LITERATUR}

\section{Profil Milenial}

Sebagai masyarakat yang lahir pada tahun 1980 sampai dengan 2000, penduduk milenial memiliki preferensi yang spesifik dalam menjalankan kehidupan mereka masing-masing. Dibekali dengan perkembangan teknologi dan nilai-nilai kesejamanan lainnya, kaum milenial memiliki pandangan tersendiri dalam menjalani hidup, sehingga terjadi pergeseran gaya hidup yang signifikan dibanding generasi sebelumnya. 
Dengan demografi Indonesia yang menempatkan penduduk milenial sebagai populasi terbanyak pada dekade ini (34\% dari populasi keseluruhan Indonesia atau setara dengan $\quad 92$ juta jiwa) maka sudah selayaknya masyarakat milenial mulai memiliki gaya dan pandangan hidup yang independen dari generasi sebelumnya, yang secara langsung mendapatkan pengakuan diri dari seluruh penduduk akan sebuah generasi berlanjut yang ditugaskan untuk meneruskan kehidupan secara global.

Pada umumnya, milenial dicirikan dengan berbagai identitas : terlahir selaras dengan perkembangan teknologi, lebih memilih jalur instan, memiliki jiwa sosial yang tinggi, memiliki toleransi yang lebih tinggi, dapat melakukan berbagai aktivitas secara bersamaan dan lebih memilih kehidupan yang bersifat bersama ${ }^{1}$.

Dalam masa pertumbuhan kaum milenial, beragam penerapan teknologi telah dikembangkan dari prototipe yang sudah ditemukan sebelumnya sehingga menjadi suatu perangkat yang dapat diakses dan digunakan oleh masyarakat luas. Dengan demikian, setiap milenial telah mendapat bekal yang cukup untuk mengintegrasikan perkembangan teknologi mutakhir ke dalam kehidupan keseharian masing-masing.

\section{Diskursus Milenial, Tipe, Perilaku dan Kesejamanan}

Milenial, sebagaimana yang telah dilaksanakan surveinya oleh IDN Times, merupakan sebuah golongan generasi yang paham tentang perkembangan teknologi. Teknologi yang terus menerus dikembangkan mencakup beragam aspek yang melekat dalam kehidupan sehari-hari, sehingga tidak jarang ditemui penduduk milenial yang memanfaatkan dan menerapkan produk-produk teknologi ke dalam hidup mereka.

\section{MEDIA YANG DIAKSES (\%)}
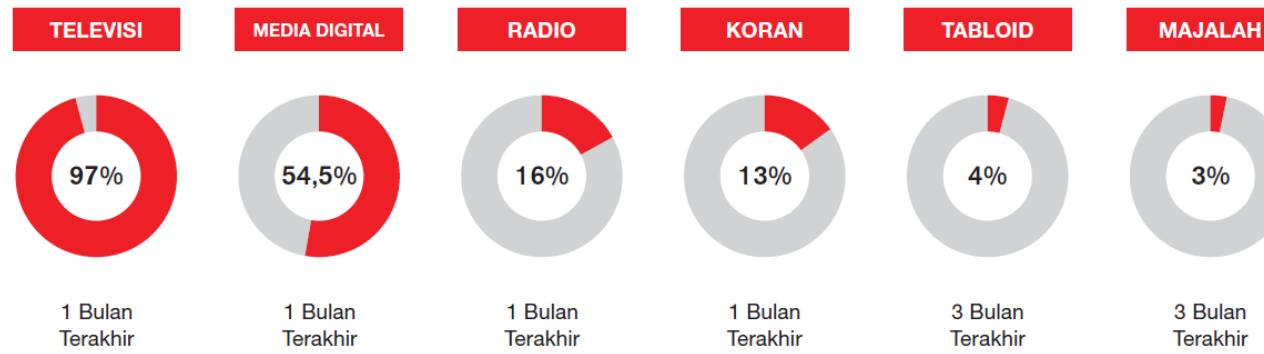

Gambar 1. Media yang Diakses oleh Milenial dalam 1 bulan terakhir Sumber: IDN Times Indonesia Millennial Report, 2019

Menurut riset CSIS 2017 dan IDN Times 2019, penduduk milenial telah beralih perangkat dalam mengakses konten informasi, baik untuk keperluan referensi pengetahuan maupun untuk mengisi waktu luang ${ }^{2}$. Paradigma kaum milenial telah menghasilkan perubahan yang signifikan dari generasi sebelumnya, dimana penduduk milenial cenderung lebih menghabiskan banyak waktu untuk mengakses konten yang bersifat digital. Berbagai gawai dipersiapkan oleh mereka untuk mengakses konten-konten yang berbasis web atau cloud computing sehingga memudahkan perpindahan informasi dan mempersingkat waktu untuk mendistribusikan informasi tersebut. Akses ke televisi telah menggeser media cetak sebagai sumber informasi teraktual. Akses ke gawai telah menggeser buku sebagai sumber referensi teraktual, meskipun beberapa konten digital masih bersifat berbayar, sehingga tidak dapat diakses oleh seluruh masyarakat secara gratis.

Pergeseran gaya hidup inilah yang seringkali dikaitkan dengan predikat malas, tidak aktif dan serba instan oleh generasi-generasi sebelumnya. Padahal, secara garis besar, milenial bergantung

\footnotetext{
${ }^{1}$ Pew Research Center. (2010). Millennials: A Portrait of Generation Next. Washington DC: Pew Research Center

2 Putra Utomo, William. (2019). Indonesia Millennial Report 2019. Jakarta: IDN Research Institute
} 
kepada gawai dan keterampilan dalam menerapkan teknologi untuk mencari informasi, referensi, dan membagikannya kepada sesama, agar dapat terjalin suatu konektivitas tiada batas waktu.

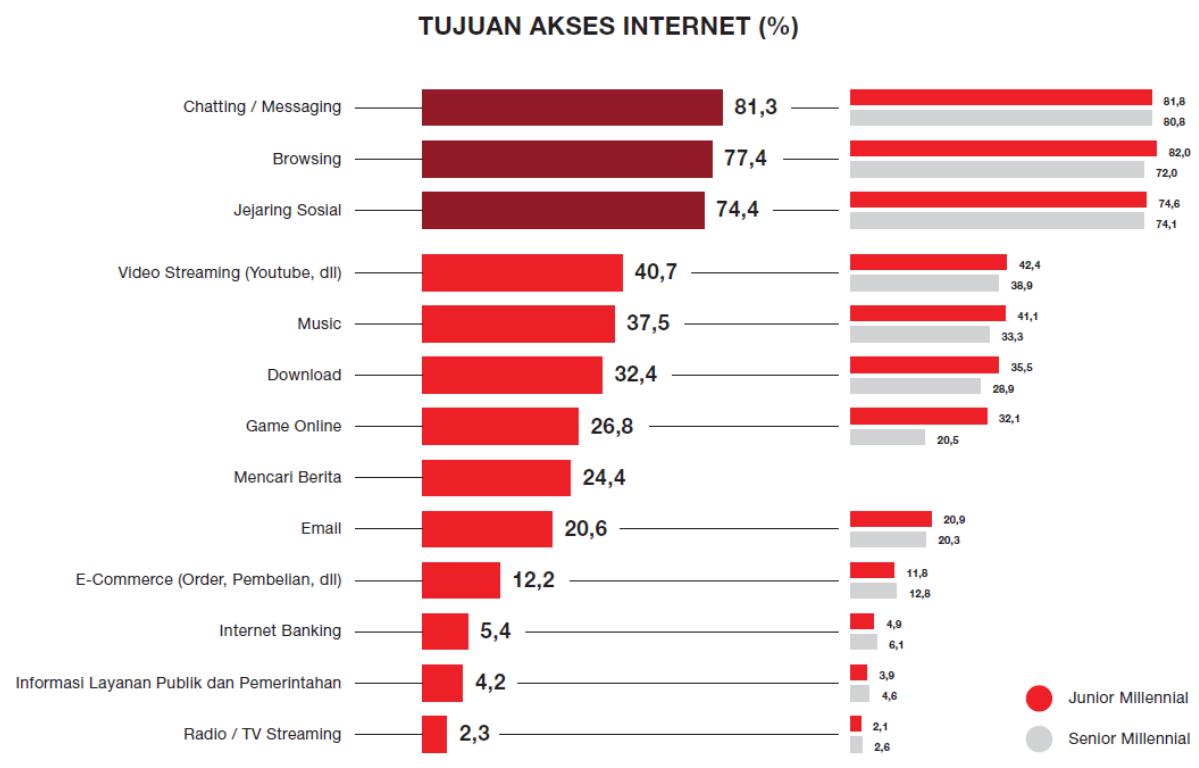

Gambar 2. Tujuan Akses Internet Kaum Milenial

Sumber: IDN Times Indonesia Millennial Report, 2019

Menurut IDN Times, tujuan akses internet untuk kaum milenial masih didominasi dengan motivasi konektivitas antar sesama (chatting/messaging $81,3 \%$ dan jejaring sosial $74,4 \%$ ) dan mencari berbagai informasi di internet (browsing $77,4 \%)^{3}$. Dengan demikian, prioritas utama masyarakat milenial lebih mengacu kepada realita kehidupan keseharian yang menjunjung tinggi jaringan antar sesama manusia.

Selain itu, sifat dasar generasi milenial yang memiliki rasa keingintahuan yang tinggi juga menjadi bekal dalam proses pembelajaran setiap individu, baik secara otodidak maupun melalui staf pengajar. Seringkali milenial mengakses konten digital untuk belajar lebih lanjut tentang minat dan hobi mereka masing-masing, sehingga mereka dapat mengembangkan diri (selfimprovement) demi menghasilkan suatu karya yang otentik dari setiap individu agar mendapatkan pengakuan, baik dari diri sendiri maupun dari lingkungan sekitar.

\section{Edukasi dan Kesejamanan}

Edukasi, layaknya teknologi, telah berkembang seiring dengan perkembangan jaman serta perilaku manusia terhadap gaya hidup dan kebutuhan. Sejarah perkembangan teori pembelajaran berawal dari teori behaviourism yang dikembangkan oleh John B. Watson pada tahun 1913. Watson mengungkapkan bahwa manusia sebagai entitas makhluk hidup belajar ketika terumuskan sebuah respon yang dapat menanggapi stimulus yang terjadi. Reflek natural yang merupakan hasil dari evolusi manusia sebagai makhluk berakal budi berperan penting dalam melahirkan pemikiran-pemikiran baru yang bersifat subjektif, sesuai dengan kapasitas masingmasing individu.

Teori cognitivism yang dikemukakan oleh Noam Chomsky menggantikan teori behaviorism pada tahun 1960. Manusia mempelajari sesuatu dengan mengandalkan orang-orang yang sudah ahli dan mahir dalam mentransferkan ilmu yang mereka miliki kepada para pelajar, sehingga terjadi sistem pembelajaran satu arah yang berasal dari guru dan berakhir di pelajar.

${ }^{3}$ lbid. 


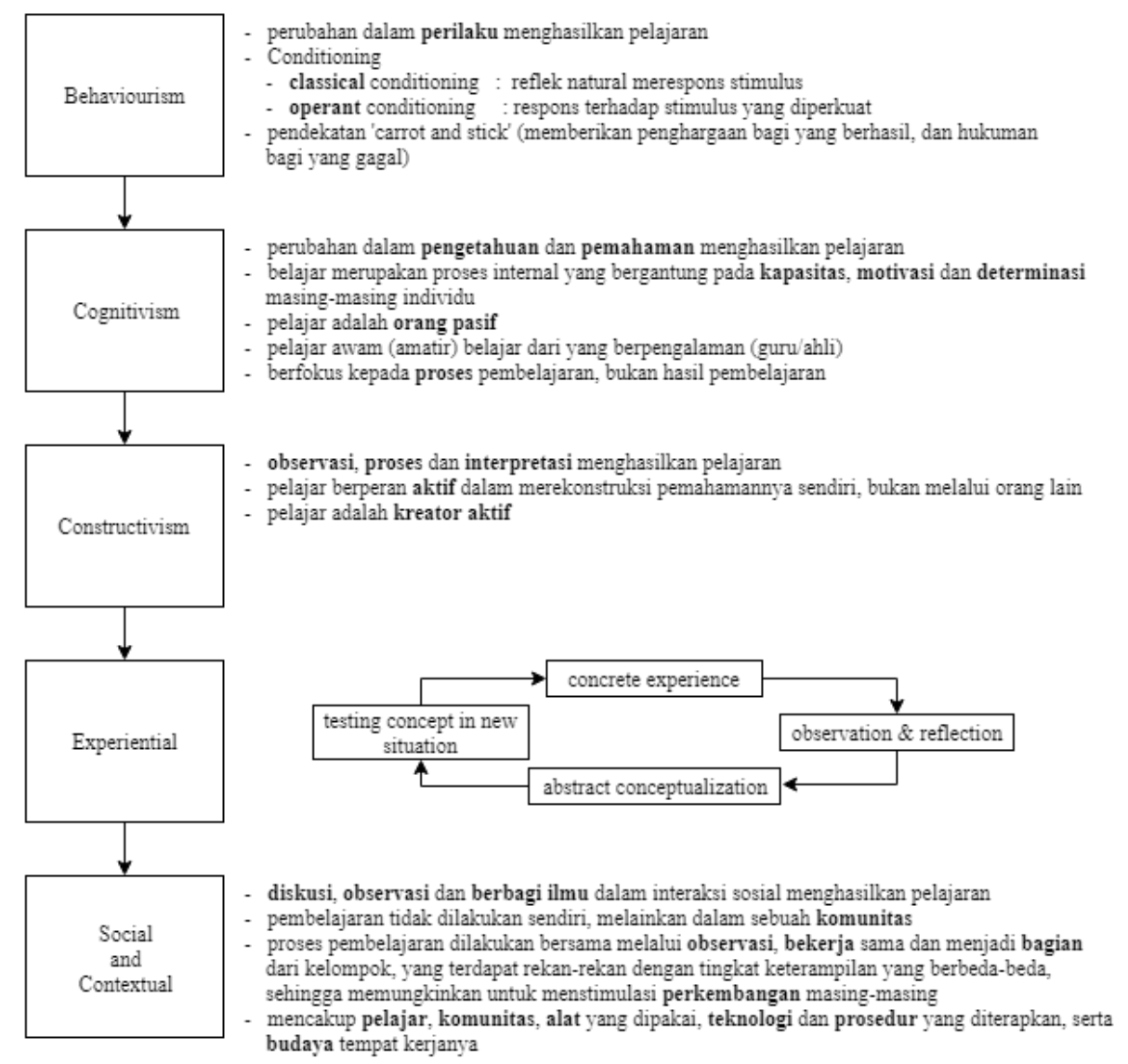

Gambar 3. Diagram Perkembangan Teori Pembelajaran Sumber: playwithlearning.com

Teori cognitivism yang dikemukakan oleh Noam Chomsky menggantikan teori behaviorism pada tahun 1960. Manusia mempelajari sesuatu dengan mengandalkan orang-orang yang sudah ahli dan mahir dalam mentransferkan ilmu yang mereka miliki kepada para pelajar, sehingga terjadi sistem pembelajaran satu arah yang berasal dari guru dan berakhir di pelajar.

Pada tahun 1978, Jean Piaget mengemukakan teori constructivism dalam sistem pembelajaran. Sistem ini menempatkan pelajar sebagai kreator aktif dengan mengijinkan mereka untuk melakukan observasi, proses dan interpretasi masing-masing sehingga dapat membentuk suatu pola kerangka berpikir yang ideal bagi setiap individu, sehingga setiap pelajar dapat memahami secara benar setiap materi belajar sesuai dengan preferensi masing-masing. Seyogyanya, constructivism dan cognitivism seringkali berjalan selaras berdampingan satu sama lain, sehingga dalam proses pembelajaran dapat lebih efektif untuk mencapai target yang ditentukan.

Teori experiential dikemukakan oleh David Kolb sebagai pengganti teori constructivism. Teori ini mengutamakan pengalaman sebagai pembelajaran bagi setiap individu sehingga masingmasing individu memiliki pemahaman yang beragam dan dapat diaplikasikan kepada pengalamanpengalaman baru.

Pada abad ke-21 ini, teori pembelajaran yang sedang menjadi acuan dalam proses belajar adalah teori social and contextual. Sebagai makhluk sosial yang tidak dapat lepas dari ketergantungan satu sama lain, manusia dituntut untuk dapat saling berkolaborasi dan bekerja sama, membentuk suatu komunitas belajar yang interaktif sehingga dapat menghasilkan suatu capaian pembelajaran secara bersama. Dalam sebuah komunitas, setiap individu diharapkan dapat mengembangkan potensi yang dimilikinya dengan berkonsultasi dengan individu lain yang sudah setingkat lebih maju dalam berbagai aspek. Kondisi ini lalu berubah seiring dengan perubahan materi pembelajaran, sehingga dapat menciptakan suatu iklim belajar mengajar yang 
saling mendukung satu sama lain, membuka pikiran untuk ide-ide baru yang orisinil dan otentik. Aktivitas pembelajaran juga mengacu kepada kontekstualitas lingkungan, dimana sedapat mungkin kegiatan belajar dapat langsung dipraktekkan di lingkungan realita agar para pelajar dapat mengalami sistem pembelajaran secara langsung (first-hand experience) yang dapat menghasilkan suatu kerangka pemikiran yang efektif. Pelajar tidak hanya mengetahui teori untuk menyelesaikan masalah, tetapi juga dapat mempelajari praktek yang dibutuhkan dalam menyelesaikan masalah tersebut, sehingga terjalin suatu koneksi antar fluid intelligence dan crystallized intelligence yang saling terintegrasi satu sama lain. Dengan sistem seperti ini, diharapkan setiap individu dapat merekonstruksi hubungan yang dalam tentang ide-ide abstrak dan aplikasi yang telah dipraktekkan.

\section{METODE}

Metode tipologi perancangan menjadi dasar dari pembentukan perancangan proyek yang mengacu kepada perkembangan fungsi perpustakaan, diawali dari prototipe sebagai gudang arsip hingga stereotipe di jaman sekarang sebagai ruang komunal. Tipologi berfungsi untuk mendalami fungsionalitas dan pembentukan ruang dalam dan luar.

Dalam perancangan fungsi bangunan perpustakaan yang diusulkan untuk dijadikan sebagai sebuah living space untuk generasi milenial, pendekatan metode tipologi sebagai pedoman perancangan digunakan agar dapat mengetahui perkembangan secara internal (perihal program ruang dan fungsi bangunan) dan eksternal (perihal penentuan dan analisa tapak dan gubahan massa).

Awal mula fungsi perpustakaan dimulai dari pembentukan ruang arsip (sekitar 3000-2000 tahun sebelum masehi). Ruang arsip mengalami perkembangan menjadi ruang belajar (400 tahun sebelum masehi-750 AD). Dalam perkembangannya, ruang belajar digunakan untuk mendapatkan ilmu pengetahuan secara langsung dari guru (terpelajar) dengan sistem pembelajaran konstruktivisme. Perpustakaan berubah menjadi ruang percetakan yang difungsikan oleh para penulis buku untuk mencetak dan menjual karya tulisnya masing-masing. Pada abad ke-17, perpustakaan beralih ke ruang riset yang digunakan oleh pelajar untuk mencari referensi sebagai bagian dari sistem pembelajaran. Dewasa ini, perpustakaan dijadikan sebagai wadah third space, sebuah ruang komunal yang digunakan oleh masyarakat sekitar untuk dijadikan titik temu maupun ruang rekreatif.

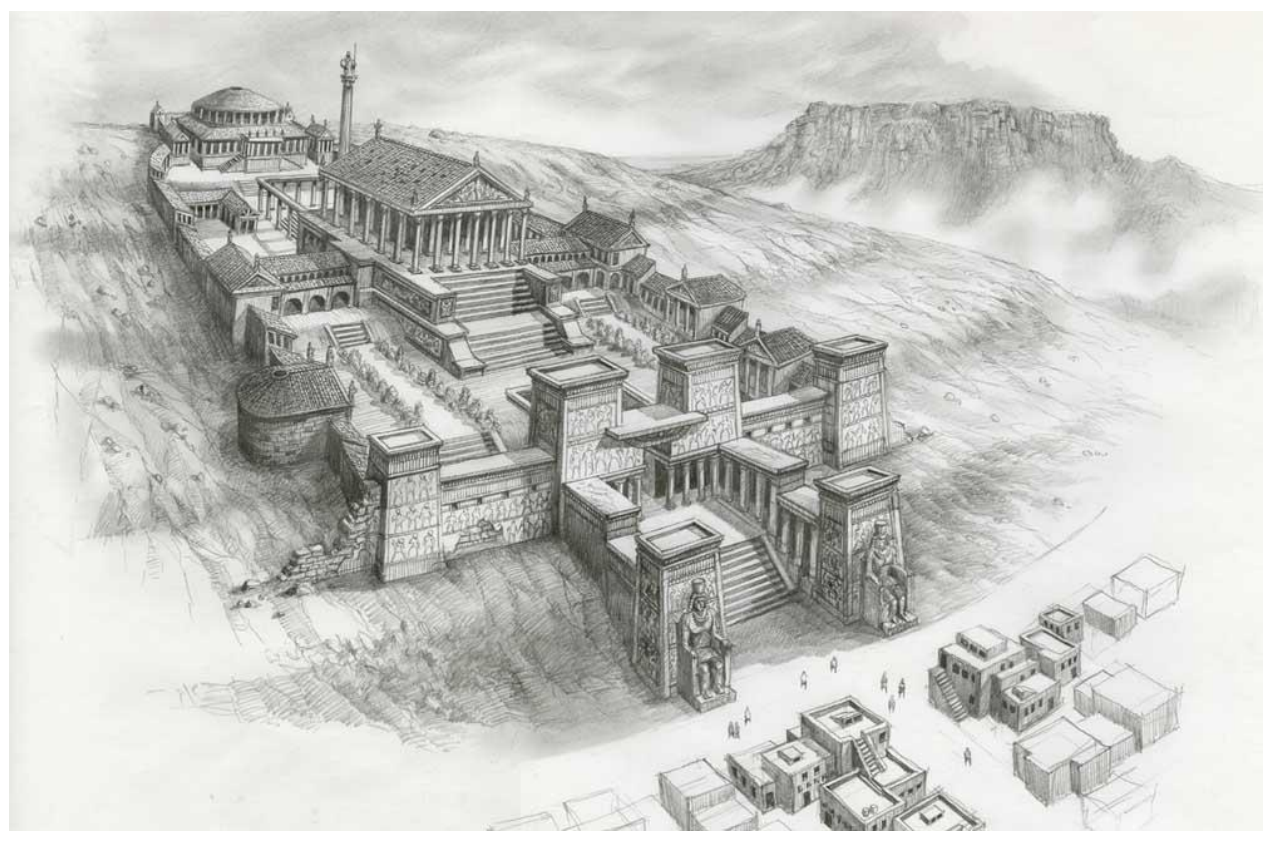

Gambar 4. Ilustrasi Perpustakaan Alexandria

Sumber: Crystalinks, 2014 


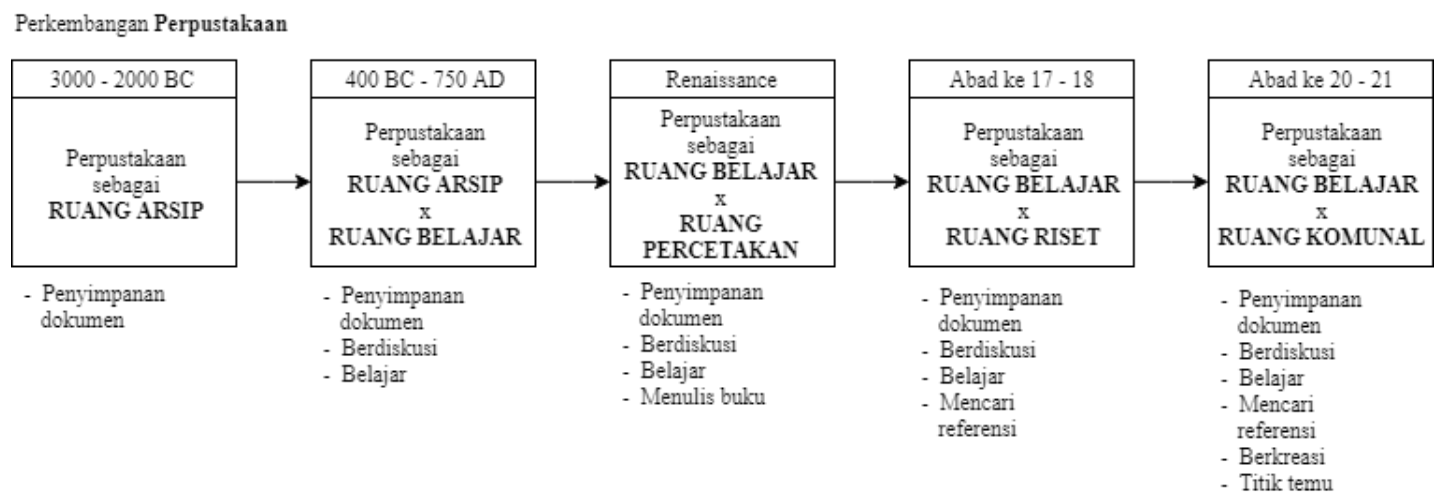

Gambar 5. Perkembangan Tipologi Perpustakaan Sumber: Penulis, 2019

Pembaharuan konsep perpustakaan yang mengikuti tren pengguna ini juga melahirkan fungsifungsi baru yakni perpustakaan yang difungsikan sebagai sebuah community space. Dipandang sebagai sebuah public living room, community space ini bertujuan untuk mewadahi segala aktivitas yang bersifat edukatif dan inspiratif, dimana pengguna dapat bersosialisasi, bertukar pikiran, belajar bersama di dalam satu wadah sebagai wujud pengembangan diri bagi para milenial dan non-milenial.

\section{DISKUSI DAN HASIL}

Demi mewadahi kesempatan bagi pengguna milenial untuk melakukan pengembangan diri secara intelektual dalam bidang teknologi digital, maka diperlukan suatu wadah edukatif khusus bagi mereka untuk dapat mempelajari secara langsung tentang teknologi dan perkembangannya (hands-on experience), ataupun wadah yang disediakan sebagai ruang diskusi atau seminar yang bertujuan untuk mendapatkan ilmu pengetahuan dan wawasan akan teknologi digital yang lebih luas.

Didukung dengan lokasi tapak yang berada di kawasan Slipicon Valley, sebuah kawasan yang dipenuhi oleh perusahaan-perusahaan yang bergerak di bidang teknologi digital, sebuah wadah third place perpustakaan lab (lab-rary) berbasis teknologi digital menjadi solusi yang tepat untuk menjawab kebutuhan para pekerja milenial yang memiliki keingintahuan yang tinggi serta keinginan untuk mengembangkan potensi diri masing-masing. Adapun perusahaan-perusahaan digital yang memiliki kantor di kawasan tersebut adalah:

$\begin{array}{ll}\text { - Start-up } & : 41 \text { perusahaan (Tokopedia, Traveloka, Airy Rooms, } \\ & \text { Gogonesia, dll.) } \\ \text { - Venture Capitalist (VC) } & : 3 \text { (East Asia, Mountain Kejora, Cyber Agent) } \\ \text { - Incubator } & : 3 \text { (Merah Cipta, Ideabox, Founder Institute) } \\ \text { - Coworking Space } & : 2\end{array}$




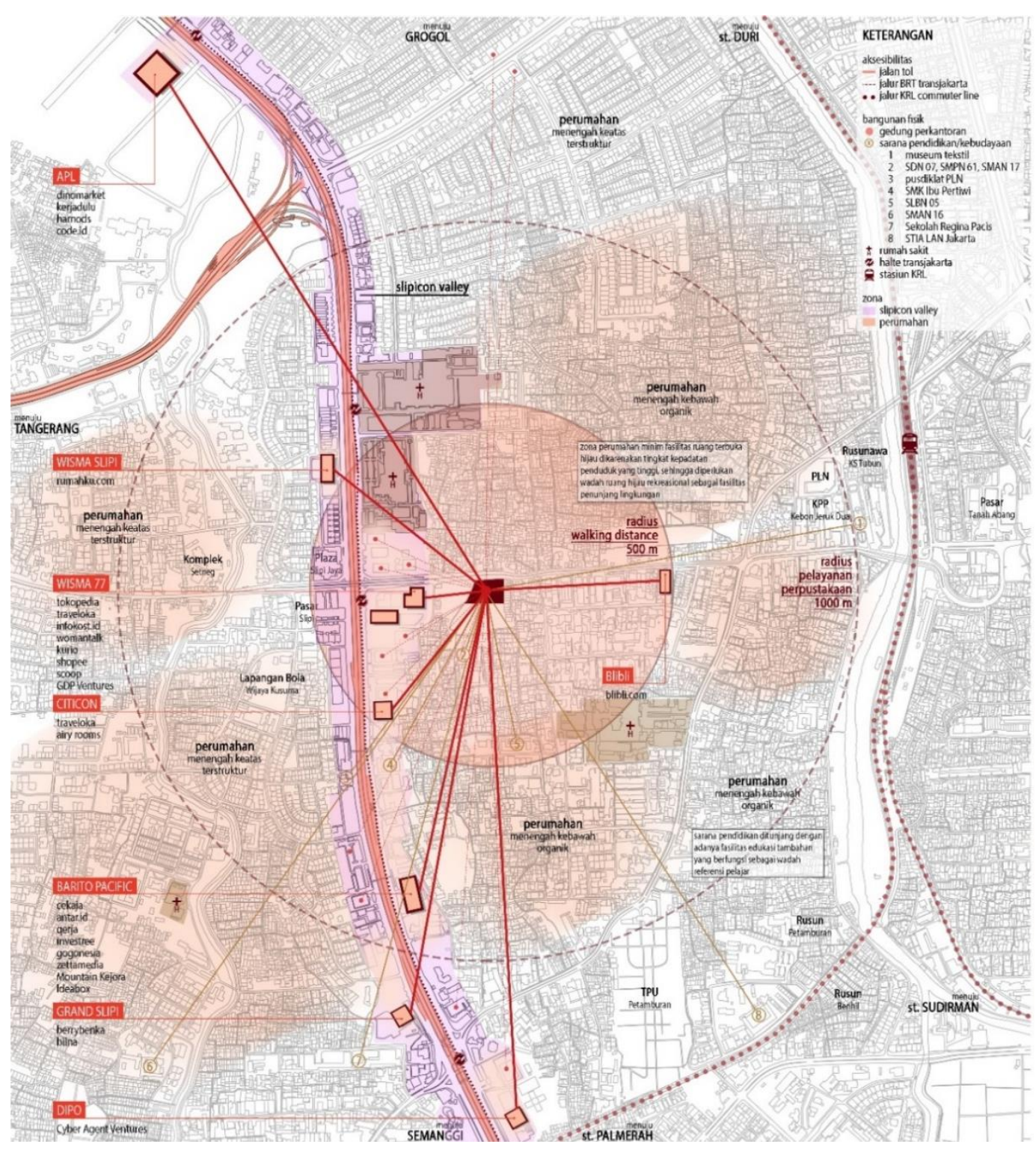

Gambar 6. Pendataan Tapak Meso

Sumber: Penulis, 2019

Dengan perusahaan-perusahaan yang dipekerjai dan didirikan oleh para milenial, maka tapak yang telah ditentukan menjadi spesifik ditunjukkan untuk para milenial yang berkantor di kawasan Slipi serta masyarakat sekitar yang memiliki keinginan untuk mengembangkan diri dengan mengikuti kelas/seminar teknologi atau mencoba bereksperimen dengan berbagai software dan hardware di laboratorium teknologi maupun menghabiskan waktu luang dengan berdiskusi atau membaca koleksi buku ragam jenis di perpustakaan umum.

Target pengguna perpustakaan lab ini mencakup para fresh graduate atau mahasiswa aktif (dan pengguna non-spesifik lainnya) yang bekerja di sekitar kawasan Slipi. Perpustakaan lab ini ditargetkan untuk digunakan pada jam luar kantor, yakni jam sebelum masuk kantor (06.0009.00), jam istirahat siang (12.00-14.00) dan jam pulang kantor (17.00-22.00). Jam operasional perpustakaan lab mencakup 16 jam (06.00-22.00) agar lebih fleksibel menyesuaikan dengan pengguna milenial yang mayoritas merupakan pekerja kantoran start-up (meskipun jam kerja perusahaan start-up juga sangat fleksibel dan bebas).

Pembentukkan gubahan massa mengikuti urban fabric lingkungan sekitar dengan memperhatikan pola sirkulasi jalan dan gugusan massa yang dibentuk. Massa beranjak dari geometri dasar persegi yang dikembangkan sesuai dengan kontekstualitas tapak agar dapat menyesuaikan dengan lingkungan sekitar yang mayoritas memiliki gubahan persegi, baik 
perumahan maupun bangunan perkantoran. Massa mengadopsi sistem terasering untuk membentuk human scale dan skyline, serta menciptakan ruang semi-outdoor berkanopi yang digunakan sebagai welcoming space. Massa dibelah di lantai bawah sebagai dasar dari pembentukan aksis menerus yang menghubungkan jalan utama (Jl. Brigjen Katamso) - tapak perencanaan - rumah susun (dalam tahap perencanaan) - institusi pendidikan sekolah dasar, menengah dan atas. Aksis ini dibentuk atas dasar pertimbangan aksesibilitas pejalan kaki yang diperlukan bagi rumah susun untuk dapat mencapai jalan utama, sekaligus menjadi titik berat ruang komunal yang berorientasi mengarah ke aksis tersebut (aksis pejalan kaki ini wajib dapat diakses 24 jam).

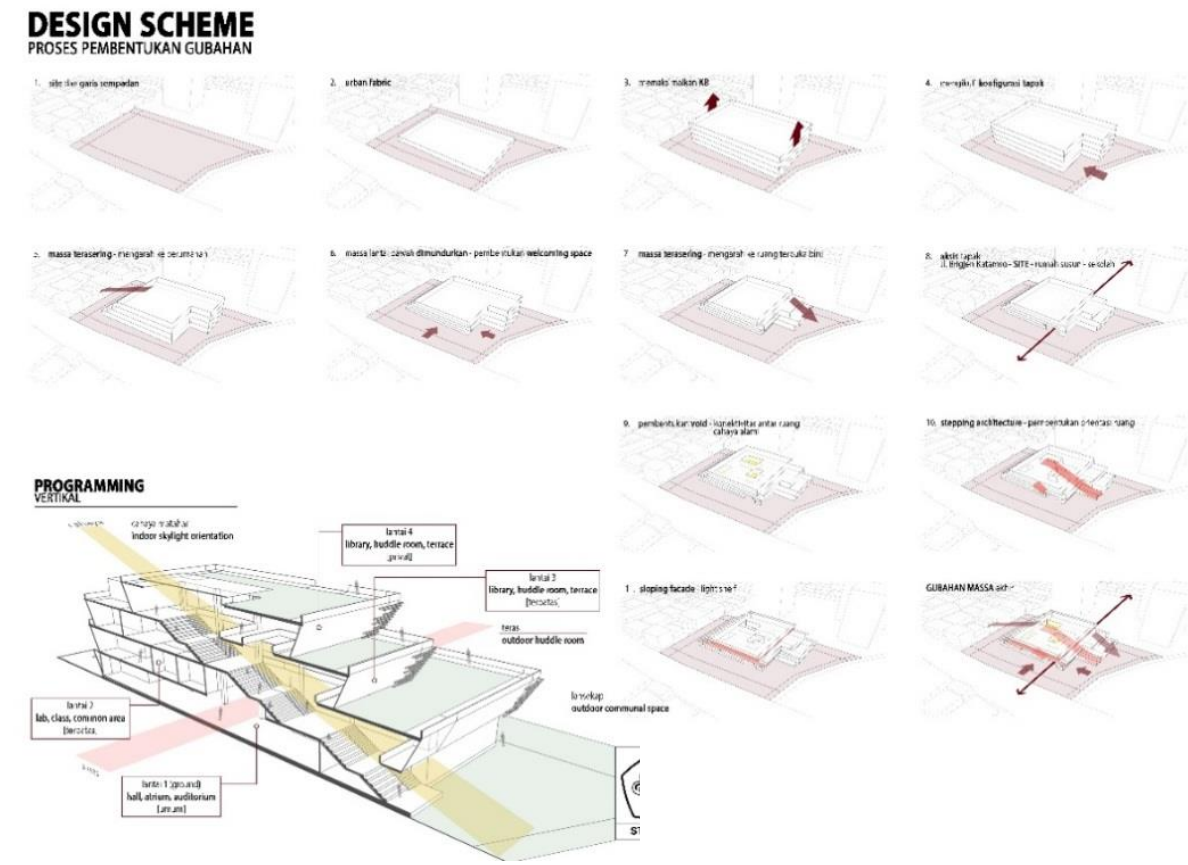

Gambar 7. Design Scheme

Sumber: Penulis, 2019

Perpustakaan lab (lab-rary) berbasis teknologi digital memiliki dua fungsi utama yang menunjang kegiatan edukatif pengembangan diri milenial : perpustakaan buku konvensional dan digital dan laboratorium praktik digital. Kedua fungsi utama ini ditunjang dengan berbagai fungsi penunjang lainnya yang berpotensi untuk dijadikan wadah living room, tempat untuk berdiskusi dan berbagi pengalaman dan pengetahuan, bagi para kaum milenial. Fungsi penunjang tersebut meliputi exhibition hall sebagai tempat pameran karya pribadi, auditorium untuk kegiatan tertutup dan privat, café untuk titik temu serta ruang terbuka hijau outdoor yang difungsikan sebagai ruang publik untuk digunakan oleh siapapun, dikarenakan ruang terbuka hijau di kawasan Slipi tergolong cukup minim dalam radius 500 meter dari tapak perencanaan. Dengan demikian, tapak diusahakan untuk dapat memaksimalkan ruang hijau terbuka baik di ground level maupun di lantai-lantai tingkat lainnya. 


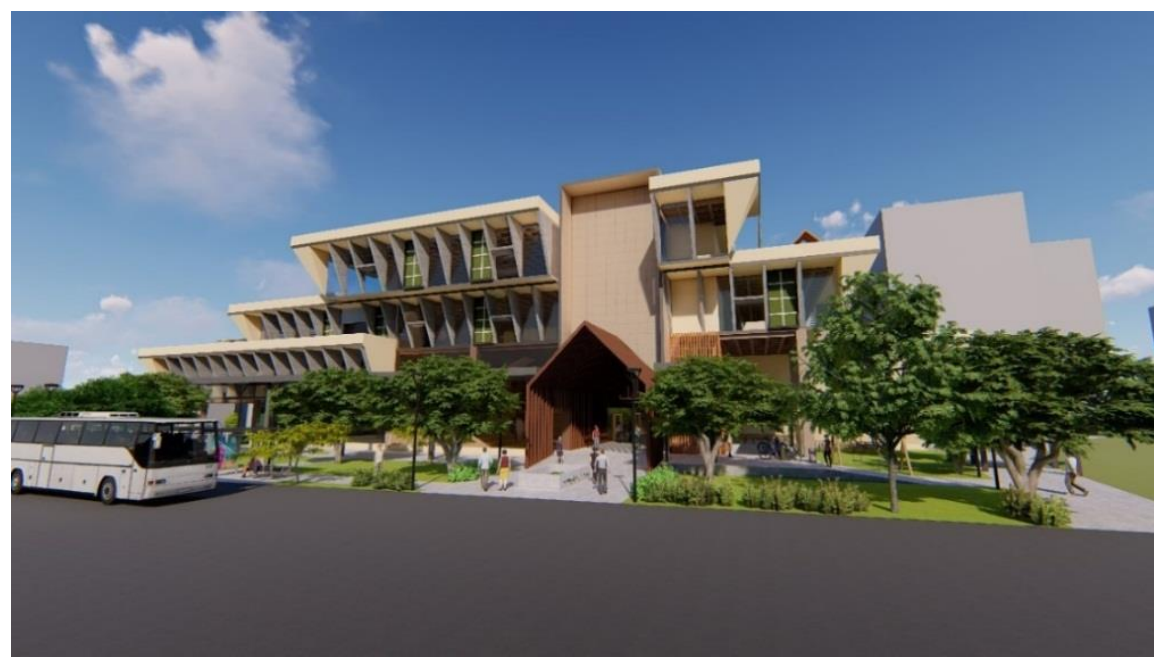

Gambar 8. Perspektif Eksterior Sumber: Penulis, 2019

Program ruang utama yang ditawarkan di dalam perpustakaan lab (lab-rary) ini terbagi menjadi beberapa zona mengikuti hierarki ketinggian bangunan berupa:

Tabel 1. Program Ruang Utama Lab-rary

\begin{tabular}{llll}
\hline Zona & Lantai & \multicolumn{1}{c}{ Ruang } & \multicolumn{1}{c}{ Deskripsi Ruang } \\
\hline Umum & Ground & Exhibition hall & $\begin{array}{l}\text { Ruang pamer karya individu atau kolaboratif (baik } \\
\text { secara internal maupun disewa untuk pameran } \\
\text { eksternal) }\end{array}$ \\
\hline & & Auditorium & Ruang kegiatan seminar/diskusi \\
\hline Terbatas & 2 & Taman & Titik temu/kumpul \\
\hline & Lab elektro & Ruang eksperimen circuitboard (hardware) \\
\hline & Lab desain & Ruang eksperimen software \\
\hline & Lab praktik & Ruang eksperimen serbaguna \\
\hline & Lab fabrikasi & Ruang eksperimen perakitan \\
\hline & Lab digital & Ruang eksperimen digital (3D printing, dll.) \\
\hline & Kelas serbaguna & \\
\hline Privat & Perpustakaan & Ruang baca pengunjung \\
\hline & Idealab & Ruang diskusi kolaboratif \\
\hline & Perpustakaan & Ruang baca pengunjung \\
\hline
\end{tabular}

Sumber: Dokumen Pribadi, 2019

Setiap laboratorium yang diusung di dalam program ruang memiliki fungsi yang berbeda-beda, sehingga ditargetkan untuk pengguna yang berbeda menyeseuaikan dengan minat setiap individu. Laboratorium-laboratorium eksperimen memiliki spesialisasi di bidang masing-masing yang memungkinkan untuk berkolaborasi antar satu dua bidang yang berbeda sehingga menciptakan inovasi yang berkesinambungan satu sama lain. Ruang-ruang common area dibentuk di setiap tempat kosong sebagai ruang transisi yang dapat digunakan para kreator untuk berdiskusi dan saling berbagi. 


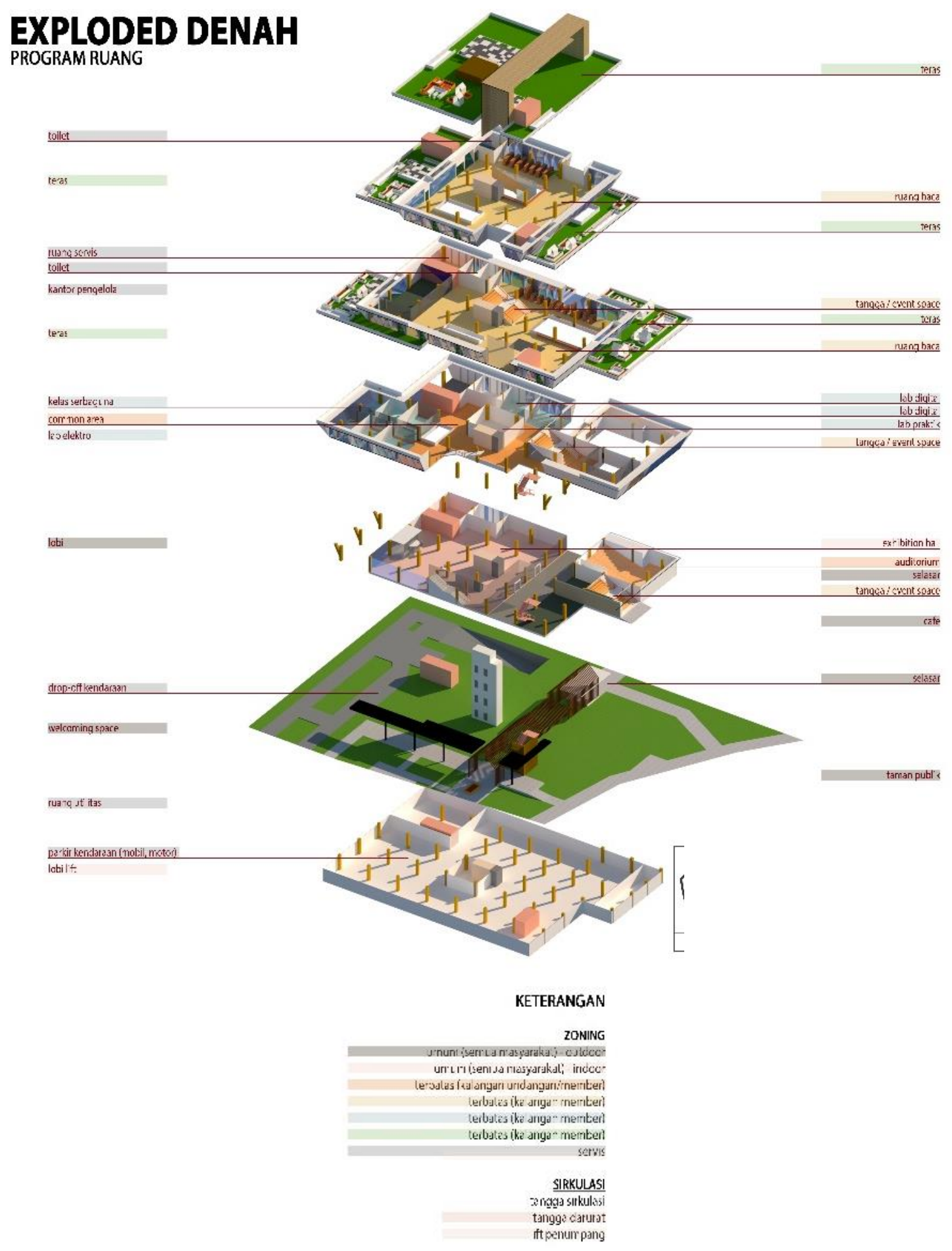

Gambar 9. Exploded Denah

Sumber: Penulis, 2019

Perpustakaan lab (lab-rary) mengusung konsep transprogramming yang diaplikasikan ke dalam ruang-ruang bangunan. Tangga sirkulasi dirancang untuk dapat difungsikan sebagai tribun untuk kegiatan diskusi atau sebagai tempat berkumpul, dimana sewaktu-waktu tirai transparan dapat membatasi ruang tribun agar memberikan ruang privasi tertutup untuk kegiatan tersebut. Ruangruang di dalam tidak dibatasi dengan tembok masif, melainkan partisi yang dapat dibuka tutup agar fungsi ruangan menjadi lebih fleksibel menyesuaikan kapasitas dan kebutuhan penggunanya. 


\section{POTONGAN PERSPEKTIF}

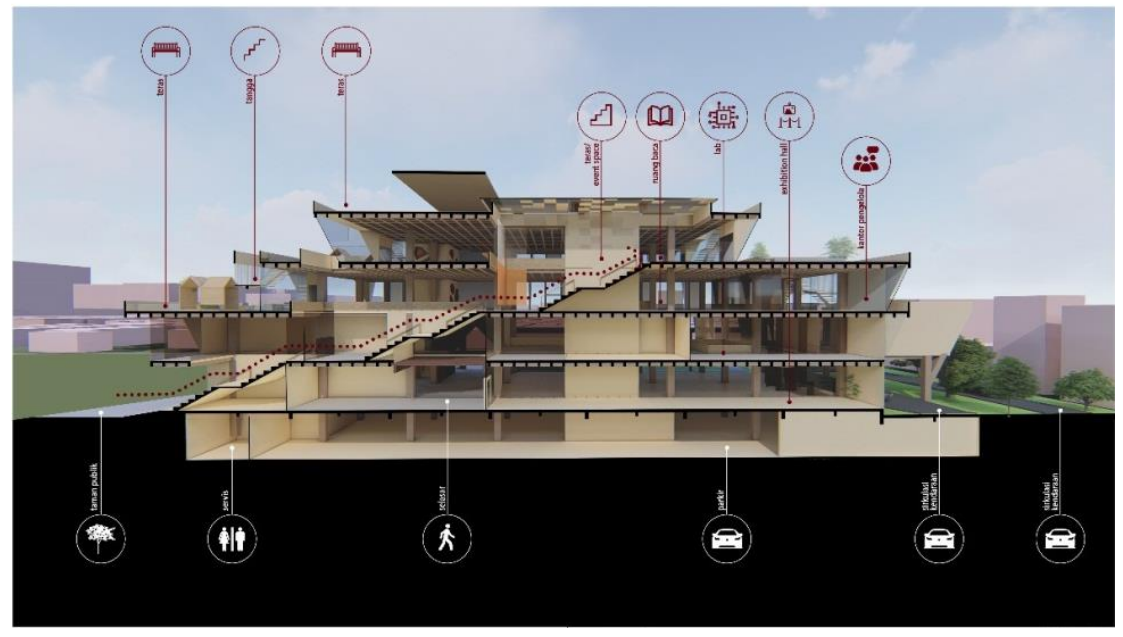

Gambar 10. Potongan Perspektif Sumber: Penulis, 2019

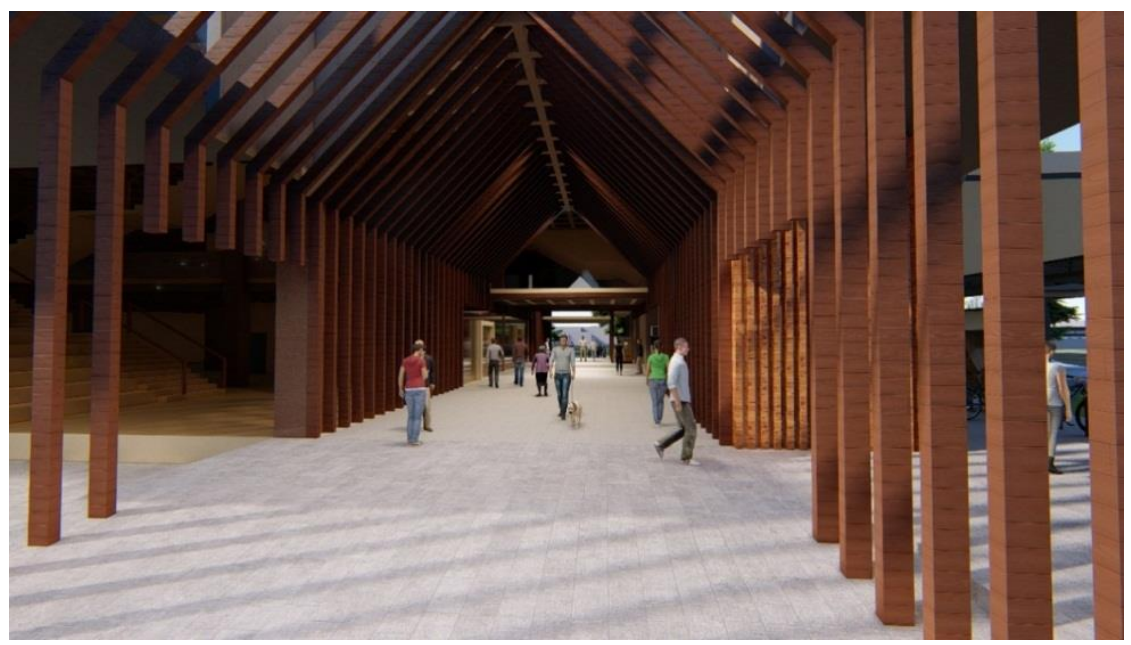

Gambar 11. Perspektif Selasar Aksis Utama Sumber: Penulis, 2019

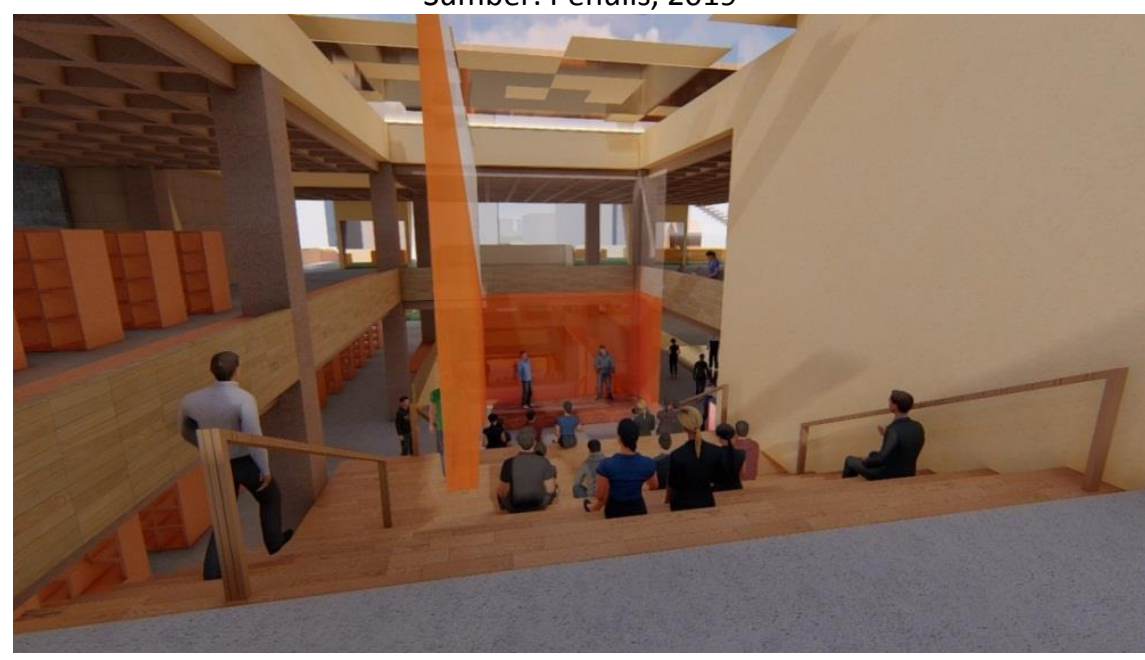

Gambar 12. Perspektif Tangga/Event Space

Sumber: Penulis, 2019 


\section{KESIMPULAN DAN SARAN}

Untuk menjawab solusi penduduk milenial Jakarta akan sebuah wadah yang dapat meningkatkan pengembangan diri lebih lanjut, maka diperlukan suatu institusi edukatif yang bertujuan untuk mewadahi pembelajaran eksperimental dan sosial dan kontekstual ke dalam suatu ruang perpustakaan laboratorium berbasis teknologi digital. Perpustakaan tidak lagi dipandang sebatas ruang pencarian referensi untuk kegiatan diskusi, tetapi juga sebagai ruang komunal living room yang bertujuan untuk mempertemukan seluruh lapisan masyarakat di dalam suatu wadah yang membantu mereka untuk berinteraksi, bekolaborasi dan berdiskusi satu sama lain sehingga dapat menciptakan suatu inovasi terbaharukan yang dapat berdampak positif terhadap masyarakat luas dalam bidang teknologi digital.

Perpustakaan lab digital ini selayaknya mewadahi pertemuan antar ahli dan amatir dalam berbagai bidang, yang menjembatani pembagian ilmu-ilmu pengetahuan baru yang dapat mendukung proses pengembangan diri setiap individu. Proses pembelajaran ini dituangkan di dalam wadah perpustakaan yang bersifat mandiri dan independen serta laboratorium yang bersifat kolaboratif. Dengan target pengguna fresh graduate dan mahasiswa aktif, diharapkan wadah ini memfasilitasi pertukaran pikiran antar dunia pendidikan dan dunia pekerjaan yang memiliki keterikatan kuat.

Dirancang dengan konsep third living space, perpustakaan lab ini memiliki peran utama dalam mewadahi aktivitas kolaborasi dan interaksi, saling berbagi dan bekerja sama antar sesama kaum milenial (senior maupun junior) agar dapat terjalin suatu konektivitas yang memungkinkan untuk membangun pemikiran kolaboratif dan menciptakan suatu peluang baru dalam mendukung sistem ekonomi kreatif yang sedang berjalan.

\section{REFERENSI}

Actiu. (2016). Designing for the Millennial Generation. Diunduh 5 Januari 2019, dari https://www.actiu.com/en/articles/news/designing-for-the-millennial-generation/

Alvara Research Center. (2016). Indonesia 2020 : The Urban Middle Class Millennials. Jakarta : Alvara.

Badan Pusat Statistik. (2018). Profil Generasi Milenial Indonesia. Jakarta : BPS.

Center for Strategic and International Studies. (2017). Orientasi Sosial, Ekonomi dan Politik Generasi Milenial. Jakarta: CSIS

Jenkins, R. (2017). This is Why Millennials Care so Much about Work-Life Balance. Diunduh 3 Januari 2019, dari https://www.inc.com/ryan-jenkins/this-is-what-millennials-value-mostin-a-job-why.html

John, G. (2016). Designing Libraries in $21^{\text {st }}$ Century. London: British Council

Khalil, F. (2016). A Millennial's Guide to Designing for Millennials. Diunduh 5 Januari 2019, dari https://www.zeuxinnovation.com/designing-for-millennials.htmINielsen. Millennials on Millennials: Digital Music and Digital Communication. New York: Nielsen Holdings

Nielsen. (2017). Millennials on Millennials: Lots of Love, Lack of Loyalty. Diunduh 2 Januari 2019, dari https://www.nielsen.com/us/en/insights/news/2017/millennials-on-millennials--lotsof-love-lack-of-loyalty.html

Oldenburg, R. (1999). The Great Good Place. Washington DC: Da Capo Press

Pew Research Center. (2010). Millennials: A Portrait of Generation Next. Washington DC: Pew Research Center

Putra, U. (2019). Indonesia Millennial Report 2019. Jakarta: IDN Research Institute

Spotify. (2018). Understanding People Through Music: Millennial Edition. Stockholm: Spotify

Till, J. (2009). Architecture Depends. London: MIT Press

Perlis, M. (2017). What do Millennials want from Life?. Diunduh 3 Januari 2019, dari https://www.huffingtonpost.com/entry/what-do-millennials-want-_b_10257926 
Pew Research Center. (2016). Book Reading 2016. Diunduh 8 Januari 2019, dari http://www.pewinternet.org/2016/09/01/book-reading-2016/

Pew Research Center. (2018). How Millennials Today Compare with Their Grandparents 50 Years Ago. Diunduh 2 Januari 2019, dari http://www.pewresearch.org/facttank/2018/03/16/how-millennials-compare-with-their-grandparents/

Pew Research Center. (2018). Millennials: Confident. Connected. Open to Change. Diunduh 2 Januari 2019, dari http://www.pewsocialtrends.org/2010/02/24/millennials-confidentconnected-open-to-change/

Roth Studio. (2016). Architecture for Millennials. Diunduh 5 Januari 2019, dari https://www.roth.com.au/blog/architecture-for-millennials/ 